\title{
Oxytocin versus Misoprostol used as an induction of labour in term in early rupture of Amniotic membranes
}

\author{
Jaydeep J. Bhatu*, Ankita B. Chaudhari, Nilesh R. Chauhan
}

Department of Obstetrics and Gynecology, GMERS Medical College and Hospital, Sola, Ahmedabad, Gujarat, India

Received: 19 November 2019

Revised: 27 January 2020

Accepted: 01 February 2020

\author{
*Correspondence: \\ Dr. Jaydeep J. Bhatu, \\ E-mail: bhatujaydeep@gmail.com
}

Copyright: () the author(s), publisher and licensee Medip Academy. This is an open-access article distributed under the terms of the Creative Commons Attribution Non-Commercial License, which permits unrestricted non-commercial use, distribution, and reproduction in any medium, provided the original work is properly cited.

\section{ABSTRACT}

Background: Pre labor Rupture of membranes is a common obstetrical problem, significant event as it transforms an ordinary pregnancy into a high risk one. Majority of cases of PROM - of about $60 \%$ occur after 37 completed weeks Induction of labour is artificial. Misoprostol is receiving attention as a cervical modifier and labour induction agent. This study compares the safety and efficacy of Misoprostol with Oxytocin in labour induction in term pre labour rupture of membranes. Objective of this study was to compare the safety and efficacy of Misoprostol with that of Oxytocin in labour induction in PROM. The effects were compared between primipara and multipara in a selected sample.

Methods: General condition is assessed by pulse rate, blood pressure, height, weight with particular attention to pedal odema, anemia. Cardiovascular and respiratory systems were examined, rule out cephalo pelvic disproportion and for Bishop's scoring. USG for foetal maturity, Liquor status and for foetal well-being. Admission CTG.

Results: There is no significant difference was observed between two groups either in vaginal delivery or in incidence of LSCS. Mean induction delivery interval in misoprostol group for nullipara is 8.5 hours. For multipara it is 6.6 hours. And in oxytocin group for nullipara is 10:4 hours. In multipara it is 6.5 for primipara it was significantly reduced in misoprostol group compared to syntocinon group.

Conclusions: Misoprostol is an effective, cheap, safe, stable at room temperature and easy to use if it is used in appropriate dosage for induction of labour in pre-labour rupture of membranes at term.

Keywords: Early rupture of membranes, Induction of labour, Meconium stained liquor, Misoprostol, Neonatal intensive care unit, Oxytocin

\section{INTRODUCTION}

Prelabour Rupture of membranes is a common obstetrical problem. It is a significant event as it transforms an ordinary pregnancy into a high risk one. Overall incidence is 5-10\%. ${ }^{1}$ Authors like Ianios (1965) and Lebher (1963) diagnose PROM only when a latent period of 1-12 hours has elapsed following amniorrhexis occurring at any time prior to the onset of labour, regardless of period of gestation.
Majority of cases of PROM - of about $60 \%$ occur after 37 completed weeks. PROM is a significant event that transforms pregnancy into a high risk one by increasing maternal and neonatal morbidity and mortality. Maternal complications like Chorioamnionitis, puerperal fever are more common in PROM., ${ }^{1,2}$ Active management of PROM decreases complications and associated maternal and neonatal morbidity and mortality. Induction of labour is artificial or non-spontaneous initiation of uterine contractions that leads to progressive cervical dilatation 
and effacement resulting in delivery of baby or products of conception. ${ }^{3,4}$

Since early days of 1950's when Oxytocin was synthesized, induction of labour has become more popular and accepted as an option in the management of PROM.

Misoprostol, a methyl ester of PGE1 is being under trial for past few years in induction of labour. Misoprostol is receiving attention as a cervical modifier and labour induction agent.

This study compares the safety and efficacy of Misoprostol with Oxytocin in labour induction in term prelabour rupture of membranes.

The present study is undertaken to compare the safety and efficacy of Misoprostol with that of Oxytocin in labour induction in PROM.

The effects were compared between primipara and multipara in a selected sample.

\section{Objectives}

- To study the effect on labour induction and compare the induction - delivery interval between 2 drugs.

- To compare the mode of delivery between 2 groups.

- To compare the foetal and maternal adverse effects between 2 drug groups.

- To compare the maternal and foetal outcome between 2 drug groups.

- To assess the cost effectiveness between 2 drugs.

\section{METHODS}

This study was carried out in GMERS Medical College and Hospital, Sola, Ahmedabad.

Prospective randomized control study from July 2017 to June 2018.

Sample size determined by statistical analysis.

Statistical analysis was done using chi square test and student ' $t$ ' test used in appropriate places. About 200 women were randomized to either Misoprostol or Oxytocin.

Diagnosis of pre labour rupture of membranes made on the basis of history, clinical examination, and speculum examination and confirmed with USG.

\section{Inclusion criteria}

- Singleton pregnancy

- Cephalic presentation

- Bishop's score $<4$
- Completed 37 weeks of gestational age

- Live fetus showing no signs of fetal compromise on admission CTG.

\section{Exclusion criteria}

- Multiple pregnancy

- Non cephalic presentations

- Bishop's Score $>4$

- H/o previous scar, Uterine Surgery

- Any medical conditions complicating pregnancy

- Hydramnios, IUGR, Gestational age < 37 weeks

- Women in labour

- Suspected chorioamnionitis.

At the time of entry into study name, age, status of booking, immunization, menstrual

History, marital history, obstetrical history, medical and personal history were noted down.

General condition is assessed by pulse rate, blood pressure, height, weight with particular attention to pedal odema, anemia. Cardiovascular and respiratory systems were examined. Obstetrics examination includes size of uterus, lie, presentation, attitude, foetal heart sound and rate, liquor adequacy and estimated foetal weight pelvic examination was done to rule out cephalopelvic disproportion and for Bishop's scoring. USG done for foetal maturity, liquor status and for foetal well-being. Admission CTG done.

\section{Methods of application}

\section{Misoprostol}

Informed consent obtained for Misoprostol group of patients. In dorsal position $25 \mu \mathrm{g}$ of Misoprostol inserted into posterior fornix and patient is advised to lie down in left lateral position for 30 minutes. Dose is repeated at the interval of 6 hours to the maximum of 3 doses.

\section{Oxytocin}

As infusion pump in not available, Oxytocin infusion started intravenously in either normal saline/Ringer lactate at dose of $8 \mathrm{drops} / \mathrm{mt}(5 \mathrm{mU} / \mathrm{mt})$ incremented at 30 minutes interval to the maximum of $48 \mathrm{drops} / \mathrm{mt}$ (30 $\mathrm{mU} / \mathrm{mt}$ ) and monitored with Oxytocin chart.

For all patients progress of labour was monitored with partogram. During induction following parameters are monitored.

- Maternal pulse rate, temperature, blood pressure, and urine output

- Uterine contractions for their frequency, duration and strength

- Fetal heart rate 
- Onset of various stages of labour.

Duration of labour and mode of delivery were notified. Caesarean section was resorted to whenever fetal distress arises or for failed induction or for failure to progress with minor degrees of cephalopelvic disproportion. Babies were followed up in neonatal unit, whenever they got admitted. Mother and baby were discharged in good condition and followed up to six weeks.

After delivery when mother and baby were discharged from hospital, advice was given for postpartum follow up. Clinical evaluation of mother and fetus was scheduled at 2 weeks after delivery and followed up to 6 weeks.

\section{RESULTS}

- Distribution of patients under the age group $\leq 20$ years is significantly more in Misoprostol group $(32 \%)$ compared to Oxytocin group (13\%).

- Distribution of patients in age group between 20-35 years is significantly more in Oxytocin group (83\%) compared to Misoprostol group (66\%).

- Mean age between 2 groups is not statistically significant $\mathrm{p}=0.2, \mathrm{t}=1.27$. (Table 1$)$.

Table 1: Age distribution between two groups.

\begin{tabular}{|lllll|}
\hline \multirow{2}{*}{ Age in years } & Misoprostol (100) & & Oxytocin (100) & \\
\hline$\leq 20$ & No. of patients & \% & No. of patients & \% \\
\hline $21-35$ & 32 & $32 \%$ & 13 & $13 \%$ \\
\hline$<35$ & 66 & $66 \%$ & 83 & $83 \%$ \\
\hline
\end{tabular}

$\mathrm{X}^{2}=10.63, \mathrm{p}=0.004$.

- For Primipara vaginal delivery in Mispostol group is - $85.56 \% \mathrm{LN}+2.6 \%$ vaccum and in Oxytocin group $76 \% \mathrm{LN}+2.6 \%$ vaccum. But this difference is statistically not significant $\mathrm{p}=0.38$.

- Incidence of LSCS for primipara in Misoprostol group is $(11.84 \%)$ and in Oxytocin group is
(21.5\%.). But this difference is statistically not significant $\mathrm{p}=0.48$.

For multipara no significant difference was observed between two groups either in vaginal delivery or in incidence of LSCS (Table 2).

Table 2: Mode of delivery between two groups.

\begin{tabular}{|llllllllll|}
\hline $\begin{array}{l}\text { Mode of } \\
\text { delivery }\end{array}$ & $\begin{array}{l}\text { Misoprostol } \\
\text { Nullipara } \\
\mathbf{( 7 6 )}\end{array}$ & $\mathbf{\%}$ & $\begin{array}{l}\text { Multipara } \\
\mathbf{( 2 4 )}\end{array}$ & $\mathbf{\%}$ & Nullipara (75) & $\mathbf{\%}$ & $\begin{array}{l}\text { Multipara } \\
(\mathbf{2 5})\end{array}$ & \% \\
\hline Normal delivery & 65 & 85.56 & 22 & 91.67 & 57 & 76 & 23 & 92 \\
\hline LSCS & 9 & 11.84 & 2 & 8.33 & 16 & 21.4 & 2 & 8 \\
\hline Vaccum & 2 & 2.6 & - & - & 2 & 2.6 & - & - \\
\hline Total & $\mathbf{7 6}$ & $\mathbf{1 0 0 \%}$ & $\mathbf{2 4}$ & $\mathbf{1 0 0 \%}$ & $\mathbf{7 5}$ & $\mathbf{1 0 0 \%}$ & $\mathbf{2 5}$ & $\mathbf{1 0 0 \%}$ \\
\hline
\end{tabular}

Table 3: Induction of labour to delivery interval between two groups.

\begin{tabular}{|lllllllll|}
\hline $\begin{array}{l}\text { Duration } \\
\text { in hours }\end{array}$ & $\begin{array}{l}\text { Misoprostol (100) } \\
\text { Nullipara } \\
\mathbf{( 7 6 )}\end{array}$ & $\mathbf{\%}$ & $\begin{array}{l}\text { Multipara } \\
(\mathbf{2 4 )}\end{array}$ & $\mathbf{\%}$ & $\begin{array}{l}\text { Nullipara } \\
\mathbf{( 7 5 )}\end{array}$ & $\mathbf{\%}$ & $\begin{array}{l}\text { Multipara } \\
(\mathbf{2 5})\end{array}$ & \% \\
\hline$<12$ & 66 & 86.84 & 22 & 91.66 & 52 & 72.22 & 23 & $92 \%$ \\
\hline $12-24$ & 1 & 1.31 & - & - & 7 & 9.33 & - & - \\
\hline$>24$ & - & - & - & - & - & - & - & - \\
\hline
\end{tabular}

Primipara "p" $=0.001$ (Significant), Multipara “p” $=0.63$ (Non-significant)

- Mean induction delivery interval in Misoprostol group for nullipara is 8.5 hours. For multipara it is 6.6 hours.
- Mean induction delivery interval in Oxytocin group for nullipara is $10: 4$ hours. In multipara it is 6.5 hours. 
- Mean induction delivery interval for primipara is significantly reduced in Misoprostol group compared to syntocinon group $\mathrm{p}=0.001$.
No statistically significant difference is observed for multipara between both the groups $\mathrm{p}=0.63$ (Table 3 ).

Table 4: PROM develops to admission interval between two groups.

\begin{tabular}{|c|c|c|c|c|c|c|c|c|}
\hline \multirow{3}{*}{$\begin{array}{l}\text { PROM-induction interval } \\
<6 \text { hours }\end{array}$} & \multicolumn{4}{|c|}{ Misoprostol (100) } & \multicolumn{4}{|c|}{ Oxytocin (100) } \\
\hline & \multicolumn{2}{|c|}{ Primipara (76\%) } & \multicolumn{2}{|c|}{ Multipara (24\%) } & \multicolumn{2}{|c|}{ Primipara (75\%) } & \multicolumn{2}{|c|}{ Multipara (25\%) } \\
\hline & 34 & $44.73 \%$ & 6 & $25 \%$ & 31 & $41.33 \%$ & 11 & $44 \%$ \\
\hline 6-12 hours & 40 & $52.63 \%$ & 18 & $75 \%$ & 42 & $56 \%$ & 14 & $56 \%$ \\
\hline$>12$ hours & 2 & $2.63 \%$ & - & & 2 & $2.66 \%$ & - & \\
\hline Mean & \multicolumn{2}{|c|}{ Misoprostol (100) } & \multirow{2}{*}{\multicolumn{2}{|c|}{ Oxytocin (100) }} & Std & & \multicolumn{2}{|c|}{$\mathrm{t}$ - test } \\
\hline PROM- induction interval & 8.6 & & & & & & & \\
\hline \multirow{2}{*}{ PROM - delivery } & \multirow{2}{*}{\multicolumn{2}{|c|}{11.68 hours }} & \multirow{2}{*}{\multicolumn{2}{|c|}{13.11 hours }} & 2.32 & & \multirow{2}{*}{\multicolumn{2}{|c|}{$\begin{array}{l}t=4.42 \\
P-0.001\end{array}$}} \\
\hline & & & & & 2.88 & & & \\
\hline
\end{tabular}

- Mean PROM - admission interval is not statistically significant between both groups.

- For Misoprostol it is $8.6 \mathrm{hrs}$ and for Oxytocin 8.2 hours
- But mean PROM - delivery interval is 11.08 hours in Misoprostol group as against 13.11 hours in Oxytocin group, which is statistically significant. $t$ test $-\mathrm{t}=4.42, \mathrm{p}=0.001$ (Table 4 ).

Table 5: Indication for LSCS in between two groups.

\begin{tabular}{|c|c|c|c|c|c|c|c|c|}
\hline \multirow[b]{2}{*}{ Indication for LSCS } & \multicolumn{4}{|c|}{ Misoprostol } & \multicolumn{4}{|l|}{ Oxytocin } \\
\hline & $\begin{array}{l}\text { Nullipara } \\
(76 \%)\end{array}$ & $\%$ & $\begin{array}{l}\text { Multipara } \\
(24 \%)\end{array}$ & $\%$ & $\begin{array}{l}\text { Nullipara } \\
(\mathbf{7 5 \%})\end{array}$ & $\%$ & $\begin{array}{l}\text { Multipara } \\
(25 \%)\end{array}$ & $\%$ \\
\hline Failed induction & 3 & 3.95 & - & - & 8 & 10.66 & - & - \\
\hline Fetal $\mathrm{D}=$ distress & 4 & 5.26 & 1 & 4.16 & 4 & 5.33 & 2 & 8 \\
\hline Failure to progress CCPD $\mathrm{I}^{\circ}$ & 2 & 2.63 & 1 & 4.16 & 4 & 5.33 & - & - \\
\hline Total & 9 & 11.84 & 2 & 8.32 & 16 & 21.22 & 2 & 8 \\
\hline
\end{tabular}

Table 6: Meconium stained liquor between two groups.

\begin{tabular}{|llll|}
\hline Presence of Meconium & Misoprostol (100) & Oxytocin (100) & Neonatal outcome \\
\hline Thick & 6 & 8 & Good \\
\hline Thin & 10 & 12 & Good \\
\hline
\end{tabular}

$\mathrm{p}=0.52$

- Failed induction as an indication for LSCS, is more in Oxytocin group (10.66\%) than in Misoprostol group $(3.95 \%)$. But this is statistically not significant.

Foetal distress incidence is not statistically different between Misoprostol group (9.42\%) and Oxytocin $(13.3 \%)$ (Table 5).

- In Misoprostol group, 6 patients were with thick meconium stained liquor, 10 patients were with thin meconium stained liquor. All are NST reactive. Of 6 thick meconium stained liquor patients, 5 were not in active phase labour and went in for LSCS and one patient in advanced labour delivered by outlet forceps. All patients with thin meconium stained liquor delivered vaginally.

- In Oxytocin group, 8 patients were with thick meconium stained liquor, 12 patients were with thin meconium stained liquor. All are NST reactive. Of 8 thick meconium stained liquor patients, 6 were not in active phase of labour and went in for LSCS, 2 patients in advanced labour delivered by outlet forceps. All patients with thin meconium stained liquor delivered vaginally.

- Neonatal outcomes were good in both groups (Table $6)$. 


\section{DISCUSSION}

This study compares the safety and efficacy of Misoprostol with Oxytocin. Of 200 patients, each 100 patients were randomized to Misoprostol and Oxytocin group. Outcomes were measured in relation to Induction delivery interval, mode of delivery, side effects, maternal and neonatal morbidity and cost effectiveness.

The latency period and time from recruitment until delivery were significantly shorter in primipara in Misoprostol group compared to Oxytocin group in the present study. Induction delivery interval for primipara in
Misoprostol group is 8.5 hours and in Oxytocin group it is 10.4 hours, $\mathrm{p}=0.001$. For multipara, inductiondelivery interval in Misoprostol group is $6.6 \mathrm{hrs}$ and in Oxytocin group is 6.5 hours, $\mathrm{p}=0.63$. This is comparable to the following studies (Table 7).

Vaginal delivery incidence observed for primipara in Misoprostol group is $88 \%$ compared to Oxytocin group $78.6 \%$.

Prevalence of LSCS in Misoprostol group for primipara is $11.84 \%$, and for multipara is $8.34 \%$ and in Oxytocin group, for primipara it is $21.4 \%$ and for multipara it is $8 \%$.

Table 7: Induction to delivery interval in different study.

\begin{tabular}{|c|c|c|}
\hline Studies & $\begin{array}{l}\text { Induction delivery interval } \\
\text { (hours) }\end{array}$ & $\begin{array}{l}\text { Present study: induction } \\
\text { delivery interval (hours) }\end{array}$ \\
\hline Fabiana de graca and colleagues ${ }^{5}$ & $11(\mathrm{p}=0.001)$ & \multirow{5}{*}{$8.06, p=0.001$} \\
\hline Kadanalis, Kumtupe $^{6}$ & $9.2(+$ or -$) 2.4 \mathrm{p}=0.001$ & \\
\hline Sanchez and Ramos and colleagues ${ }^{7}$ & $11, p=0.004$ & \\
\hline Kramer RL, Gilson GJ and colleagues ${ }^{8}$ & 585 minutes $\mathrm{p}=0.001$ & \\
\hline Chuck FJ, Huffaker ${ }^{9}$ & $11.4, p=0.001$ & \\
\hline
\end{tabular}

Table 8: Caesarean rate between different studies.

\begin{tabular}{|c|c|c|}
\hline Studies & Caesarean rate & Present study \\
\hline Fabiana de Graca collegues ${ }^{5}$ & $20 \%, p=0.22$ & \multirow{4}{*}{$20.17 \%, p=0.27$} \\
\hline Kadanalis, kumtepe $^{6}$ & $30 \%$ & \\
\hline Kramer RL, Gilson GJ and colleagues ${ }^{8}$ & $8 \%, p=0.2$ & \\
\hline Wing DA, Paul RH ${ }^{10}$ & $20.80 \%$ & \\
\hline
\end{tabular}

However, this difference is statistically not significant (Table 8).

In the present study neonatal outcomes were similar.

In Misoprostol group, six patients were with thick meconium stained liquor.

A 20-year-old primi/39 weeks of gestational age/ on admission with clear liquor, had thick meconium stained liquor on $2^{\text {nd }}$ dose of Misoprostol and in early phase of labour (NST reactive) went in for LSCS. Similarly, three primipara with term gestation on admission with clear liquor, had thick meconium stained liquor on $2^{\text {nd }}$ dose of Misoprostol and in early phase of labour (NST reactive) went in for LSCS.

A 25-year-old second gravida (G2P1L1), previous fullterm normal delivery with 40 weeks gestational age had thick meconium liquor on $2^{\text {nd }}$ dose of Misoprostol and in latent phase of labour (NST reactive) went in for LSCS.

A 29-year-old primi with term gestation had thick meconium with 1st dose of Misoprostol and in active phase of labour delivered by outlet forceps.
In Oxytocin group eight patients were with thick meconium stained liquor.

Four primi para with term gestation on admission with clear liquor had thick meconium stained liquor with Oxytocin. Infusion and latent phase of labour (NST reactive) went in for $\mathrm{LSCS}$.

Two-second gravida with term gestation on admission with clear liquor had thick meconium liquor after Oxytocin. Infusion and in latent phase of labour (NST reactive) went in for LSCS.

Two primipara with thick meconium liquor in active phase of labour were delivered by outlet forceps.

Two babies got admitted in NICU in Misoprostol groupone for low birth weight $(2.1 \mathrm{~kg})$ and other baby for mild respiratory distress (Apgar 7/10, 8/10) for observation. In Oxytocin six babies got admitted-one for low birth weight $(2 \mathrm{~kg})$ and five babies for mild respiratory distress for observation. All babies were discharged in good condition. 
In this study, one patient had vomiting of one episode, which resolved spontaneously. No other side effects were observed. And there is no statistically significant difference was observed in adverse effects between two drug groups.

\section{CONCLUSION}

Misoprostol is an effective, cheap, safe, stable at room temperature and easy to use if it is used in appropriate dosage for induction of labour in prelabour rupture of membranes at term.

Funding: No funding sources

Conflict of interest: None declared

Ethical approval: The study was approved by the Institutional Ethics Committee

\section{REFERENCES}

1. Evaldson GR, Malmborg AS - PROM and ascending infection. Brit Obstet Gynaecol. 1982;89:793-801.

2. Ngai SN, Chan YM. Misoprostol compared with syntocinon in women at term with PROM. RCOG 2000;107(2):222-7.

3. Karim SMM, Trunall RC, Hilliert K, Patel RC. Induction of labour with PGF2 $\alpha$ J. Obstet Gynaecol. 1969;76:769-89.

4. Fernandiz E, Vaila S. Fernandez E, Vavilala S. Misoprostol-a miracle drug. Obs Gynae Today. 2001;9:530-4.

5. da Graça Krupa F, Cecatti JG, de Castro Surita FG, Milanez HM, Parpinelli MÂ. Misoprostol versus expectant management in premature rupture of membranes at term. An Inter J Obstet Gynaecol. 2005;112(9):1284-90.

6. Kadanali S, Küçüközkan T, Zor N, Kumtepe Y. Comparison of labor induction with misoprostol vs. oxytocin/prostaglandin E2 in term pregnancy. Inter $\mathbf{J}$ Gynecol Obstet. 1996;55(2):99-104.

7. Sanchez-Ramos LU, Kaunitz AM, Del GV, Delke IS, Schroeder PA, Briones DK. Labor induction with the prostaglandin E1 methyl analogue misoprostol versus oxytocin: a randomized trial. Obstet Gynecol. 1993;81(3):332-6.

8. Kramer RL, Gilson GJ, Morrison DS, Martin D, Gonzalez JL, Qualls CR. A randomized trial of misoprostol and oxytocin for induction of labor: safety and efficacy. Obstet Gynecol. 1997;89(3):38791.

9. Chuck FJ, Huffaker BJ. Labor induction with intravaginal misoprostol versus intracervical prostaglandin E2 gel (Prepidil gel): randomized comparison. Am J Obstet Gynecol. 1995;173(4):1137-42.

10. Wing DA, Paul RH. Induction of labor with Misoprostol for PROM beyond 36 Week's gestation. AMJ Obstet Gynaecol. 1998:179(1):94-9.

Cite this article as: Bhatu JJ, Chaudhari AB, Chauhan NR. Oxytocin versus Misoprostol used as an induction of labour in term in early rupture of Amniotic membranes. Int J Reprod Contracept Obstet Gynecol 2020;9:1023-8. 